\title{
MATHEMATICAL MODELS DESCRIBING GENERATION AND DIFFUSION OF TRITIUM AND HELIUM-4 IN SOLID BREEDERS FOR FUSION REACTORS
}

\author{
R. M. Alire \\ S. A. Steward
}

February 8, 1977

Prepared for U.S. Energy Research \& Development

Administration under contract No. W-7405-Eng-48

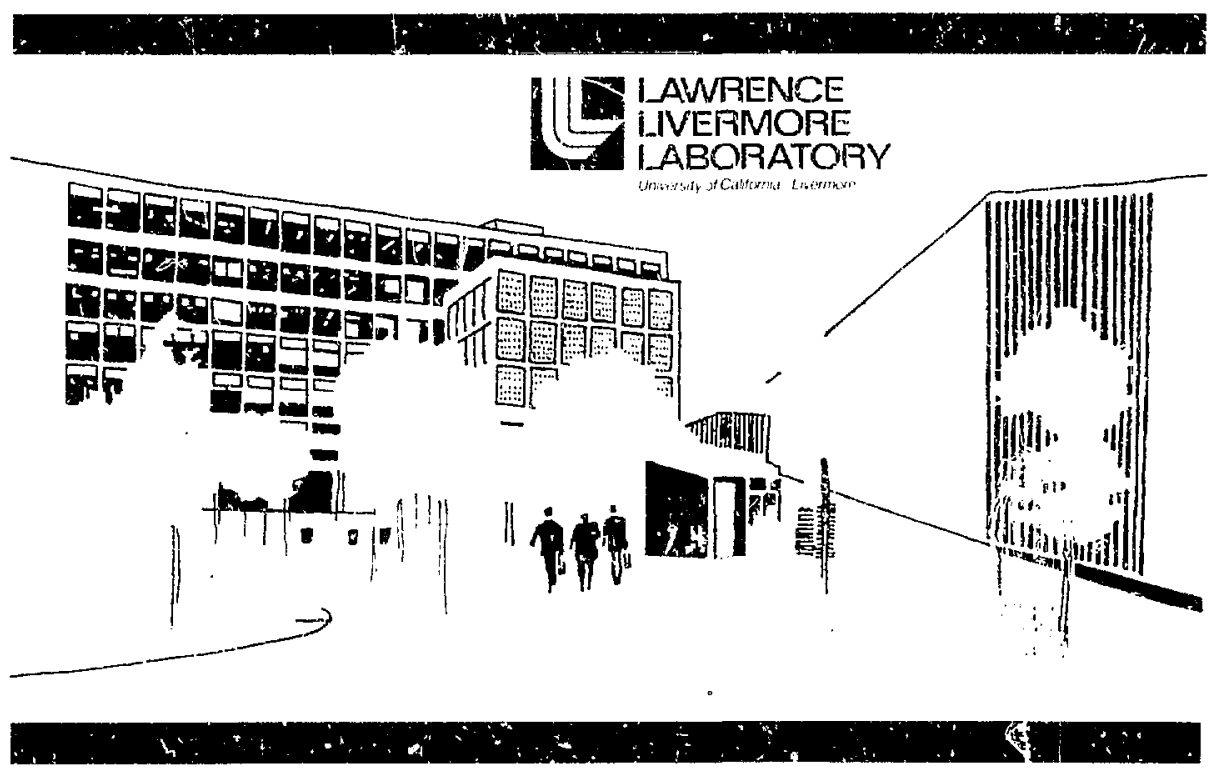




\section{Norice:}

This ter at wa pletrated at an dictrunt if witk

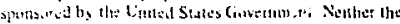

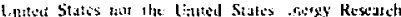

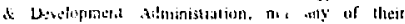

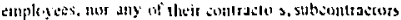

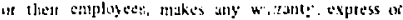
implied. on assumes any legal liabi ay of tesponsibility

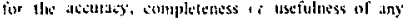

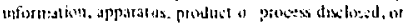
in presonts the lts llse vould sot mithes pribuldi:-anded righls,

\section{Potic:}

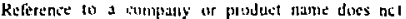
mply approma al tecinmendation of the product Iy

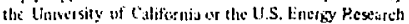

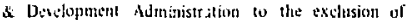
othels thot moy be suituts.

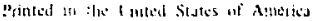

$$
\text { Ard stive from }
$$

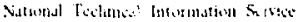

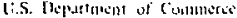

5:55 Parl Rosial Raved

Sprofictiold, Wh 2306

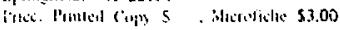

\begin{tabular}{|c|c|c|c|c|}
\hline Page Range & $\begin{array}{l}\text { Domestic } \\
\text { Price }\end{array}$ & Pagc & Aange & $\begin{array}{c}\text { Doniestic } \\
\text { Price }\end{array}$ \\
\hline Coi $0=5$ & 5.30 & $3 \% 6$ & .80 & 10.00 \\
\hline $026 \cdot 050$ & $+x$ & 351 & $3+5$ & 10.50 \\
\hline 051.075 & +50 & 376 & 1190 & 10.75 \\
\hline 076100 & S. & tol & +25 & 11.10 \\
\hline $10 ! \quad 125$ & 5,50 & itot & +50 & 11.75 \\
\hline $126 \cdot 150$ & 1.00 & +51 & $t^{45}$ & 12.00 \\
\hline $151 \cdot 175$ & 6.75 & +76 & 500 & 12.50 \\
\hline $176-200$ & 7.50 & 501 & 525 & 12.75 \\
\hline $201-2 \geq 5$ & 7.75 & $5-65$ & 550 & 13.00 \\
\hline $236-450$ & $s, 00$ & 1 & 575 & 1.3 .50 \\
\hline $251 \ldots 175$ & 1.00 & 570 & 600 & 13,75 \\
\hline $276 \ldots .360$ & 79 & 601 & แu & $\bullet$ \\
\hline $301-325$ & 17.35 & & & \\
\hline
\end{tabular}

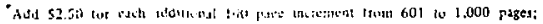

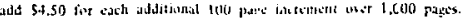




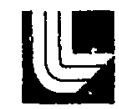

LAWRENCE IIVEFIMORE LABORATORY

university of Cahtornia Livermore.California 94550

LCRL-52212

\section{MATHEMATICAL MODELS DESCRIBING GENERATION AND DIFFUSION OF TRITIUM AND HELIUM-4 IN SOLID BREEDERS FOR FUSION REACTORS}

R. M. Alire and S. A. Steward

MS, date: Vebruary 8, 1.977

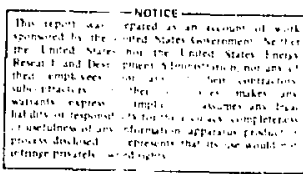




\section{Contents}

Ahstract. . . . . . . . . . . . . . . . . . . . . . 1

Introduction . . . . . . . . . . . . . . . . . . . . 1

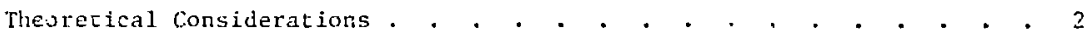

Gezeration and hccumulation of Helium-4 and Jritiun in

a Sphere. • . . . . . . . . . . . . . . . . . 2

Release of Gases. . . . . . . . . . . . . . . . . . 3

Concentration at Sphere Center . . . . . . . . . . . . . . i

Applicability of lifususion Modei . . . . . . . . . . . . . . . 4

Accumulation of Tritium in Solid by Absorption from

Scirrounding Gas and by Internal Brecdinf . . . . . . . . . . . . /

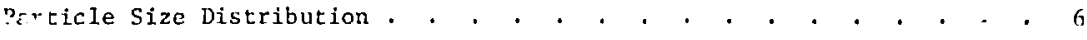

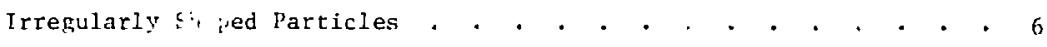

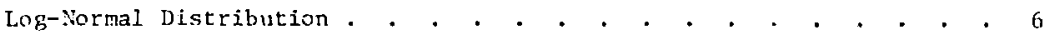

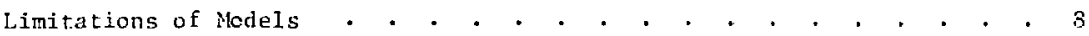

Conclusions anci Recomnendations . . . . . . . . . . . . . . 8

References . . . . . . . . . . . . . . . . . . . . . 10 


\title{
MATHEMATICAL MODELS DESCRIBING GENERATION AND DIFFUSION DF TRITIUM AND HELIUM 4 IN SOLID BREEDERS FOR FUSION REACTORS
}

\begin{abstract}
Several mathemarical models, based on spherimal geometry, were developad to describe generation, accumilation, and :elease of ${ }^{4}$ He and $T_{2}$ in solid breeders for lusion reactors. The appli.sability o: these models was extendert to include a collection of particles that have a log-normal distribution. An assessment of the models focused attention on the fact that there is a paucity of data on the diffusion coefficients and solubilities of hydrogen isotopes and helium-4 in solid breeders.

For generation rates greater than $10^{13}$ atoms $/ \mathrm{cm}^{3} \cdot \mathrm{s}$, the limiting concentrations of helium-4 and tritinm may exceed their solubilities in solid breeders, and bubbles could form. These bubbles could be accomodated by swel1ing without rupturing. In some cases the forces imparted by trapped gases may be sufficiert to rupture the sphere. In other cases new exit paths for these gasas, such as grain boundary separations, cracks, or fissures, co: $d$ be formed.
\end{abstract}

\section{introduction}

Some conceptual desigrs of fusion reactors have selected solid breeciers such wa iithium oxide $\left(\mathrm{Li}_{2} \mathrm{O}\right)$ as blanket materials. ${ }^{1,2}$ Since there are no natural sources of lxitium $\left(\mathrm{T}_{2}\right)$, all fusion reactors must breed their own tritium. In order to establish methods for recovering $\mathrm{T}_{2}$ it is of considerable importance to evaluate transport properties of $\mathrm{T}_{2}$ and ${ }^{4} \mathrm{He}$ in solid breeders and structura 1 materials.

In lithium-containing compounds the only nuclear reactions that produce tritium with a high enough cross section to be useful are ${ }^{6} \mathrm{Li}(n, \alpha) \mathrm{I}$ and ${ }^{7} \mathrm{Li}\left(\mathrm{n}, \mathrm{n}^{\prime}, \alpha\right) \mathrm{T} \cdot{ }^{1,2}$ These two neutron-induced reactions have rates that are about a factor of 10 greater than other possible gas producing nuclear reactions.

Seki ${ }^{1}$ has suggested that trapped ${ }^{4} \mathrm{He}$ in $\mathrm{Li}_{2} \mathrm{O}$ could cause swelling. Hickman ${ }^{3}$ has also stated that prolonged exposure of solid breeders to neutrons may indure swelling and internal void formation that could act as permanent sinks for much larger amcunts of trit:itm than presently expected. 
The objective of this study was to establish mathematial formution:s that would provide a method for descrioing the time-dependent aromulation and release of ${ }^{4} \mathrm{He}$ and $\mathrm{T}_{2}$ is $\quad$ ild breeders.

\section{Theorertical Considerations}

GENERATION AND ACCURRLAT ION OF HELIUN-4 AND TRITILY IX A SPHERL

The differential equations that describe heat condution in a solid sphere with a honogenous heat source were derived by Carslaw and Jagger. ${ }^{4}$ By assuming that the accumulation and release of neutron-induced gases, such as ho and $\mathrm{T}_{2}$, are analoguus processes, it is a simple nater to obtain transport equations for these gases in the solit.

For a sphere with radius a, the moles of gas retained (o) at time $t$, for t>0, witi zero initial concentration in the sphere and at the sphere surface is described $k y^{5}$ :

$$
Q=\frac{4 \pi A_{O^{a}}}{45 D}\left[1-\frac{90}{\pi^{4}} \sum_{n=1}^{\infty} \frac{1}{n^{4}} \exp \left(-n^{2} D \pi^{2} t / a^{2}\right)\right],
$$

where $\mathrm{D}\left(\mathrm{cm}^{2} / \mathrm{s}\right)$ is the diffusion coefficient of the gas in the solid, and $\mathrm{A}_{0}$ (moles $/ \mathrm{cm}^{3} \cdot \mathrm{s}$ ) is the generation rate oi the gas. At long times $(t \rightarrow \infty)$ Eq. (1) becones $\vartheta=4 \pi A_{0} a^{5} / 45 \mathrm{D}$, and the average concentration becomes $\bar{c}$ (noles $\left./ \mathrm{cm}^{3}\right)=\mathrm{A}_{\mathrm{O}^{\mathrm{a}}} \mathrm{a}^{2} / 25 \mathrm{D}$.

Equation (1) shows that the limiting quantity that accumulates in the sphere is proportional to the gas generation rate $A_{J}$ and to $a^{5}$. If diffusion is the only process by which the generated gases ${ }^{4} \mathrm{He}$ and $\mathrm{r}_{2}$ enn exit from the solid, then for generation rates greater than $10^{3}$ atoms $/ \mathrm{cm}^{3} \cdot \mathrm{s}$ the sulubilities of these gases in solids will probably be exceeded and bubbles could form.

In some cases the forces imparted by trapped gases may be sufficient to rupture the sphere. In other cases new exit paths for the gases, such as grain boundary separations, cracks, or fissu:es cculd be formed. If the forces imparted by the trapped gases are small, the trapped gases will be accomodated by swelling without rupturing.

For generation rates less than $10^{12}$ atoms $/ \mathrm{cm}^{3} \cdot \mathrm{s}$, the solubilities are not exceeded, For some app?ications this condition may be desirable for temporarily storing $T_{2}$ in the solid. 
iqquation (1) ind others that follow can be applied not only to processes with a continuous generation rate, but also to a process with a pulserl highfreruency gas generation.

\section{RELEASE OF GASES}

During exposure to neutrons not only are gases generared in litiaim containing solids, but they are also released to the surrounding gasis. For ${ }^{4} \mathrm{He}$ or $\mathrm{I}_{2}$, the amount released as a function of time can be derived by halming the amourts of gas involved. That is, the gas quantity releases = gas nuantity generated - yas quantity retained by the solid. Therefore, the quaritity released $Q_{\mathrm{R}}$ (moles) can be expressed as

$y_{R}=\frac{4}{3} r^{3} A_{0} t-\frac{4 \pi A_{0} a^{5}}{45 D}\left[1-\frac{90}{\pi^{4}} \sum_{n=1}^{\infty} \frac{1}{n^{4}} \exp \left(-n^{2} D \pi^{2} t / a^{2}\right)\right]$.

Ac lor time $(t+\infty)$, the quantity generated equals the quantity rele:aze.1; $i . e .$,

$$
\vartheta_{\mathrm{R}}=\mathrm{A}_{\mathrm{O}} \mathrm{t} \text {. }
$$

At early exposure times most of the gases geierated are retained by the rolid and the release race increases according to the fornulation

$$
\frac{d n}{d t}=\frac{4}{3} \pi a^{3} A_{U}\left[1-\frac{6}{\pi^{2}} \sum_{n=1}^{\infty} \frac{1}{n^{2}} \exp \left(-n^{2} \pi^{2} D t / a^{2}\right)\right] .
$$

A sphere size, temperature, and generation rate sould be selected such that the limiting quantity, $4 \pi \mathrm{A}^{\mathrm{a}^{5}} / 45 \mathrm{D}$, retained by the solid could be achieved in a short rime and any additional gas generated would go directly to the gas phass. Equation ( 3 ) expresses the moles released, $Q_{R}$, as a function of $t$ ime at constant temperature under these conditions.

\section{CONCENT :ITON AT SPHERE CENTER}

Interial forces tending to rupture the solid are priportional to the sum of ${ }^{4} \mathrm{He}$ and $\mathrm{T}_{2}$ concentrations at the sphere center. These concentrations can be described by the equation 6 
$c\left(\frac{i n o l e s}{c^{3}}\right)=\frac{4^{3} a^{2}}{6 D}\left[1+\frac{12}{2} \sum_{n=1}^{i} \frac{(-1)^{n}}{n^{2}} \exp \left(-m^{3} n^{2} t / a^{2}\right)\right]$.

It follows that the limitiug concentration for each gat as $t$. w becomes $A_{u^{2}}{ }^{2} / 60$.

Because in most fusion reactor applications it is easier to process $i$, in the gas phase, it would be desirable to accumilate most of the ${ }^{4}$ ile and $\mathrm{T}_{2}$ in the surrounding gas by allowing their limiting concantrations in the solict to be achieved, thereby forcing any additional gases generated to gro directly to the gas phase. A knowledge of the maximum deformation that the solid will undezgo belore rupturing is required to establish limiting concentrations. "Wo extent of deformation can only be experimentally dotermined.

APPLICABILITY OF DIFEUSION MODEL

The solubilities of $\mathrm{T}_{2}$ or ${ }^{4} \mathrm{He}$ in lithium-containing solids are not known, but they are expected to be low. It is not clear whether the accumulation or release of these gases can be described by Eqs. (1) and (2) after the solubility is exceeded and bubbles are formed. If no new exit paths are created as the solid deforms, then Eqs. (1) and (2) will probab?y describe the accumulation and release of gases.

\section{Accumulation of Tritium in Solid by Absorption from Surrounding Gas and by Internal Breeding}

It is plausible to assume that negligible amounts of $T_{2}$ are absorbed from the surrounding gas during early neutron exposures until limiting concentrations are achieved. In a containei system, after the limiting concertration $A_{0} a^{2} / 6 D$ is achioved through irradiation, the amount of $I_{2}$ surrounding the solid is expacted to be enough to allow transfer of $\mathrm{T}_{2}$ from the surrounding gas to the solid.

The in eraction between the two sources of $\mathrm{I}_{2}$ and $\mathrm{Li}_{2} \mathrm{O}$ can be assessed by assuming initial and boundary conditions that apply immediately folloving an initial neutron exposure. That is, set the conditions such that, for a new neutron exposure the starting concentration of $\mathrm{T}_{2}$ in the solid is the limiting concentration resulting from a previous neutron exposule. This constraint on the initial concentration can be described by the expressior: 


$$
\left.c(r)=\dot{s}\left(a^{2}-r^{2}\right) / 6 D\right) .
$$

in ordar to continue the derivation, we assumed that transfer of $\mathrm{T}_{2}$ into and out of the solid can be described by the formulation ${ }^{4}$

$$
\frac{d c}{d r}=h\left(c_{b}-c_{s}\right)
$$

where $h$ is a proportionality constant with units of $\mathrm{cm}^{-1}, c_{s}$ is the concentration of $T_{2}$ at the sphere surface $(x=a)$, and $c_{b}$ is the concentration of $T_{2}$ in the solid. The moles $Q$ of $T_{2}$, which come from $T_{2}$ in the surrounding gas and from neutron-induced nuclear reactions, can be described by: ${ }^{7}$

$Q=\frac{4 \pi A_{0} a^{5}}{45 D}+\left(5 V+\frac{4 \pi A O^{a^{4}}}{9 h D}\right)$

$$
\times\left\{1-6 h^{2} \sum_{n=1}^{\infty} \frac{\exp \left(-x_{n}^{2} D t\right)}{a_{n}^{2}\left[a^{2} \alpha^{2}+a h(a h-1)\right]}\right\} \text {, }
$$

where $\alpha_{n}$ is the $n: h$ nonzero positive root of

$$
A \alpha_{n} \cot a x_{n}=1-a h
$$

$S$ is the solubility of $T_{2}$ in a solid breeder, $V$ is volume of the sphere, and the remaining symbols mean the same as defined above. At long times $(t+\infty)$, the Iimiting amount $Q_{\text {max }}$ of $T_{2}$ retained by the sphere is

$$
Q_{\max }=\frac{4 \pi \mathrm{A}_{0} \mathrm{a}^{5}}{4.5 \mathrm{D}}+Q_{\infty}+\frac{4 \pi \mathrm{A} 0^{\mathrm{a}^{4}}}{9 \mathrm{hD}} .
$$

Because the value of $h$ can only be experimentally determined, it is not yet pussible to estimate $Q_{\max }$ for either ${ }^{4}$ He or $T_{2}$. 


\title{
Particle Size Distribution
}

\author{
IRREGULARIX SHAPED PARTICIES
}

The analysts described above only applies to one sphere wi to many spheres of the same size. For practical applications suli an ideal situation: will not exist, but more likely will consist of a size distribution of irregularly shaped particles.

For many regularly shaped particles the sut tact-tomolume ratio varies as $k / r$, where $k$ is a constant approximately equal to 3 and $r$ is a dimunsion surb: as radius or half-thickness. For small particles deviations from spherinul shape could be adjusted by applying a surfece-to-volume shape correction so that an irregularly shaped particle could be represented as having a regular shape such as a sphere.

\section{LOG-NORMAL DISTRIBUTION}

The log-normal distribution serves as an exceilent mortel for particil? size distribution analysis. ${ }^{8}$ It provides a convenient method for describing a dispersed Darticulate system with only two parameters.

The Normal density function is defined by:

$$
\frac{\mathrm{dn}}{\mathrm{N}}=\frac{1}{\sqrt{2}} \mathrm{e} \frac{-\mathrm{x}^{2}}{2} \mathrm{dx}
$$

where $x=(\bar{r}-r) / \sigma, r$ is particle radius, $\bar{r}$ is the arithmetic mean radius, $\sigma$ is the standard deviation and $N$ is the total number of particles. It is recognized ${ }^{8}$ that the majorlty of dispersed systems tend to follow a logarithmic variant of che normal density function. Ts $Z$ is defined as $z=\left(\overline{\eta_{n r}}-\eta_{n r_{i}}\right) / 0$ where $\overline{\ln r}=\left(\sum n_{i} l n r_{1}\right) / \Sigma n_{1}$, by making the substitution $2 n \bar{y}=\overline{\operatorname{lnr}}(\bar{y} \neq \bar{r}), z$ becomes $\left(\ln \bar{y} / r_{i}\right) / \sigma$ resulting in a working form of the log-normal distribution,

$$
\frac{\mathrm{dn}}{\mathrm{N}}=\frac{1}{\sqrt{2 \pi}} \exp \left(-z^{2} / 2\right) \mathrm{dz}\left(\ell_{n}=\log _{\mathrm{e}}\right)
$$


The area of an indjujulual sphere is $A=4 \pi\left(r_{i}\right)^{2}=4: .(\bar{y})^{2} \exp (-2 c 2)$ and the total area of a powder can be expressed as:

$$
A=\frac{4 \pi \mathrm{y}(\bar{y})^{2}}{\sqrt{2 \pi}} \int_{-\infty}^{+\infty} \exp \left(\frac{-z^{2}}{2}-2.0 \%\right) \mathrm{d} \pi
$$

which integrates to:

$$
A=4 \ldots N(\bar{y})^{2} \exp \left(-2 g^{2}\right)
$$

Similarly, the total volumis is:

$$
v=\frac{4}{3} \frac{i N}{\sqrt{27}}(\bar{y})^{3} \int_{-\infty}^{+\infty} \exp \left(-30 z-\frac{z^{2}}{2}\right) d z
$$

which results in:

$$
V=\frac{4}{3} \pi(\bar{y})^{3} \exp \left(\frac{9}{2} \sigma^{2}\right)
$$

The surface-to-volume ratio is uniquely defined with two parameters $\sigma$ and $\bar{y}$ as follows: $\mathrm{A} / \mathrm{V}=3 / \ddot{y} \exp \left(-5 / 2 \sigma^{2}\right)$.

We can extend the analysis from one sphere to include all spheres by super aposing the $\log$-noimal distribution to Eqs. (1), (5), or (6). For example, by combining Eqs. (1) and (9) the average concentration $\bar{C}$ in all spheres having a log-normal distribution can be described by the expression:

$$
\begin{aligned}
\bar{c}= & \frac{\Lambda_{0}(\bar{y})^{2} i e^{2 \sigma 2}}{S 2 \pi D} \int_{-\infty}^{+\infty} e^{-\frac{1}{2}(x+2 \sigma)^{2}} \\
& \times\left[1-\sum_{n=1} \frac{1}{n^{4}} e^{\left.-n^{2} D \Pi^{2} t / N(\bar{y})^{2} e^{2} \sigma^{2} e^{-\frac{1}{2}(x+20)^{2}}\right] d x .}\right.
\end{aligned}
$$




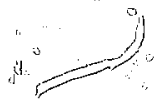

A complete particle size analosis would he necessary to decermine the empirical paranters $\bar{y}$ and $\because$. The expected behavor ot spherical purtiols should not be large for nonspherical particles of comparable a iminsiuns. large deviations from suherical georiegtry, which might occur from extreme irre, ilarities, would be manifested as errozs in the average dimension and would change the empirical determination of the diffupion constant $D$.

\section{Limitations of Models}

It is reasonable to question the ralidicy of the mathematicat models used or these assessments. It is unrealistic to believe that the initial and boundary conditions used for obtaning the various solutions rigidly apply"to fusion reactors. These conditions and the resulting equations ars only intended to represent approximate conditions in a fusion reactor, sut are used because they simplify the probiems sufficiently so that the appropriate differential equations can be analytically sulved.

Since long-cime extrapolations from the models ate not strongly dependent on the geometry pasted as a frame of reference, the limiting values are useful for any regular geometry. On the other hand, the liniting values are strongly dependent on the i:itial conditicns assumed. A better definition of the gnditions in a fusion reactor are nevessary to refine tine mathematical descriptions and to allow a more realistic representatic of line time dependence and limiting values.

\section{Conclusions and Recommendations}

$\mathrm{An}$ assessment of some problems associated with tritium and helium-4 geaeration and accumulation in solids as blanket materials can be made by using sphericaI geometry as a frame of reference for $\mathrm{Li}_{2} 0$ particles. The evaluation can be conveniently extended to:include a distribution of particles that can be adequately represented by a log-normal distrihitior.

perhaps the most useful part of the study is that it focuses actention on some areàs where ro experimental information is availatie. We can gnly provide information of lasting value by experimentally determining the appropriate constants $S$ and $D$. The following experiments are listed in order to delingate itose arcas where experimentail work is soreiy needed. 
- betermine solubility and diffusion constants for $\mathrm{T}_{2}$ and He and mixtures of both in sclid breeders.

- Determine the accumulation rates of $\mathrm{T}_{2}$ and 4 He in solid breeders when both gases are generated in the solid as well. at absorbed from the gas phase. This experinent would be done by exposing in the temperature range $1000-1300^{\circ} \mathrm{K}$, a solid breeder to neutrons.

- Determine the amount of deformation that a solid breeder can undergo sefore rupturing by exposing it to neutrons and allowing gas bubbles of $\mathrm{T}_{2}$ and ${ }^{4}$ He to corm.

- Lse techniques such as transmission electron microscopy and nuclear magnetic resonance to study bubble formation.

- Scudy the release mechanisms and how they are affected by deformation of the solid.

- Determine an optimum particle size that will provide effective gas reicase and minimize the $\mathrm{T}_{2}$ inventory. 


\section{References}

1. Y. Seki, ․ that. Soi. ari pech. 12, 769 (1975).

2. J. Maniscalo, Reactor Conapts for Laser Fusion, Lawrence Livermote Laboratory Internal Document SS\&A 76-132 (1976). Readers outsjla the Laboratory who desire further information on LLL internal dacu:itnts shouid address their Inquiries to the Technical Information Department, Lawrence Livermore Laboratory, Livermore, California 94550.

3. R. G. HAckman, Fuel Cyele Problems in Fusion Reoctors, Lamrance Livermore Laboratory, Report UCRL-77645 (1976).

4. H. S. Carslaw and J. C. Jaeger, "Conduction of Heat in Solids", (CIarendon Press, Oxford, 1959, pp. 243-247.

5. Equation (1) was obtained by converting heat conductivity to gas diffusivity and integrating Eq. (6). Equation (b) is fousd on p. 243 of Ref. (4).

6. Equation (5) was obtained by converting heat conductivity to gas diffusivity and evaluating the concentration at: the sphere center.

7. Equation (7) was obtained by converting heat conductivity to gas difrusivity and integrating the equation found on p. 246 of Ref. (4).

8. J. E. Smith and M. L. Jordan, J. Colz. Soi., 19, 549 (1964).

$\mathrm{MSG} /$ a $\mathrm{E} / \mathrm{mla}$ 